\title{
Surgical removal of eyes in a tertiary institution in North eastern Nigeria
}

Authors: Olatunji F.0., Ibrahim F.U., Ayanniyi A.A., Azonobi R.I., Tukur R.B., Maji D.A. Correspondence to: Dr Fatai 0 Olatunji, Ophthalmology Department, University of Ilorin Teaching Hospital, Ilorin. P.O.Box 1003, Asunara, Ilorin. Kwara State, Nigeria, GSM: +234 8033912863 E-mail: drfolatunji@yahoo.co.uk

\section{Abstract}

\author{
Background \\ Surgical eye removal is performed for various end-stage eye diseases to \\ provide adequate comfort, replace volume and give good functional and \\ cosmetic appearance. The pattern of eye removal is unknown for North \\ Eastern Nigeria. \\ Objective \\ To determine the indications for eye removal in the study community. \\ Method \\ Records of all the patients whose eyes were removed between January \\ 2002 and December 2008 were reviewed retrospectively. Age, sex, \\ diagnosis and type of surgery were recorded. \\ Results \\ A total of 67 eyes were removed during the period consisting of 46 males
}

(68.7\%). Mean age was 29.5 years (range 4 months to 90 years). Indications for surgery were trauma, 26 (38.8\%), infection, 21 (31.3\%), anterior staphyloma, 14 (20.9\%), tumor 4, (6.0\%) and painful blind eye, 2 (3.0\%). Evisceration was performed in 55 (82.1\%), enucleation, 11 (16.4\%) and exenteration, $1(1.5 \%)$ patient. In children $(n=28)$, the indications were trauma and anterior staphyloma in 10 patients (35.7\%) each, tumor in 4 (14.3\%), infection in 3 (10.7\%) and painful blind eye (mooren's ulcer) in 1 (3.6\%) of the children respectively. In adults $(n=39)$, indications were infections, 18 (46.2\%), trauma, 16 (41.0\%), anterior staphyloma, 4 (10.3\%) and painful blind eye due to advanced glaucoma, 1 (2.6\%).

Conclusion

Trauma, infections, and anterior staphyloma were the major indications for eye removal. Most of the indications were avoidable.

\section{Introduction}

Enucleation or evisceration is performed for various end-stage eye diseases. The affected eye is removed to provide adequate comfort from pain in painful blind eyes of any etiology, to replace volume and give good cosmetic appearance in phthisis and anterior staphyloma, to prevent spread of infection and malignancy in infectious and malignant diseases and reduce risk of sympathetic ophthalmia from penetrating eye injuries (1). Evisceration involves the removal of the corneal leaving an intact scleral shell. Enuclecation is the removal of the entire diseased globe from the orbit, by separating its connections (extra ocular muscles and the optic nerve). In exenteration the globe and all (total exenteration) or part (partial or modified exenteration) of the orbital soft tissues and ocular adnexas are removed. Indications for each procedure vary with changing trends in disease management and may reflect the pattern of severe ocular diseases in a given community.or the level of advancement in management of ocular diseases. Apart from trau- ma that is a common indication for eye removal in both developed and developing worlds (2-6), the more common indications in the developed world are intraocular malignancy $(3,7-9)$ and a blind, painful eye $(3,10,11)$. In most reports from developing world infections (pan ophthalmitis) $(4-6,12)$ and sequelae of preventable corneal diseases are still common $(12,14)$. The study centre is a tertiary health institution in Bauchi state, in the north eastern geopolitical zone of Nigeria. Although many studies on indications for eye removal have been carried out in Nigeria, majority are in the southern parts of the country $(4,5,12)$. The north eastern zone of the country has the highest prevalence of blindness out of the 6 geopolitical zones (13). The community is underserved. Prior to 2002 there was no full time opthamologist in the hospital. Other ophthalmologists including most of the co-authors in the study, practice in the centre part-time during their holidays/leave periods. The study objective was therefore to determine the indications for eye removal in the study community. 


\section{Methods}

Records of all the patients who underwent surgery for eye removal by evisceration, enucleation or exenteration between January 2002 and December 2008 were reviewed retrospectively. Details of age, sex, diagnosis and type of surgery were recorded. The total number of ophthalmic surgeries performed during the period was recorded from the operation theatre register. Patients with incomplete records were excluded. Specific history of preceding ocular trauma was ruled out in all cases of primary infection.

Tumors were not histologically proven since the hospital laboratory had no histological services during the period and specimens were sent to the nearest teaching hospital about $200 \mathrm{~km}$ away.

\section{Results}

A total of 67 eyes of 67 patients were removed during the period consisting of 46 males $(68.7 \%)$ and 21 females $(31.3 \%)$. Male to female ratio was $2: 1$. The mean age was 29.5 (SD 26.17) years and it ranged from 4 months to 90 years (Table 1 ).

During the period, 748 ophthalmic surgeries were performed. Eye removal surgeries thus represented $8.9 \%$ of total ophthalmic surgeries.

In the year 2002 only 1 eye removal surgery was carried out as part of 6 ophthalmic surgeries for that year. In 2003 , it consisted of 5 out of the 123 ophthalmic surgeries. Similarly, in 2004, 2005, 2006, 2007 and 2008, eye removal surgeries consisted of 7 of 165,12 of 186,16 of 106, 14 of 130, and 12 of 137 ophthalmic surgeries respectively.

The diagnosis (indication for surgery) was ruptured globe (trauma) in 26 patients (38.8\%) followed by infection (panophthalmitis) in 21 (31.3\%). Anterior staphyloma was responsible for eye removal in $14(20.9 \%)$ patients, tumor in $4(6.0 \%)$ and painful blind eye in $2(3.0 \%)$ patients (Fig. 1).

The surgeries performed were evisceration in 55 (82.1\%), enucleation in $11(16.4 \%)$ patients, and exenteration in $1(1.5 \%)$ patient.

Specific etiologies were recorded in 22 patients. These included a preceding history of measles in 6 and corneal ulcer in 1 of the patients with anterior staphyloma. Similarly, in 13 of the patients with ocular trauma, 5 were due to stick injury. There was history of assault in 2 , his-

\begin{tabular}{lllll} 
Age Range & Sex & Total & & \\
\hline (Yrs) & Male & Female & No. & (\%) \\
\hline $1-10$ & 15 & 6 & 21 & 31.3 \\
\hline $11-20$ & 7 & 4 & 11 & 16.5 \\
\hline $21-30$ & 2 & 4 & 6 & 9.0 \\
\hline $31-40$ & 4 & 1 & 5 & 7.4 \\
\hline $41-50$ & 6 & 1 & 7 & 10.5 \\
\hline $51-60$ & 5 & 1 & 6 & 9.0 \\
\hline $61-70$ & 1 & 4 & 5 & 7.4 \\
\hline $71-80$ & 4 & 1 & 5 & 7.4 \\
\hline $81-90$ & 0 & 1 & 1 & 1.5 \\
\hline Total & 46 & 21 & 67 & 100 \\
\hline
\end{tabular}

Table 1:Age and Sex Distribution of the Patients Who's Eyes Were Removed

tory of bullhorn injury in 2 and goat horn injury in one. Others were due to injuries sustained from a hoe in the farm, road traffic accident, fall from a height, accidental firearm explosion and a fan blade in one patient each. The 2 cases of painful blind eyes were due to end stage glaucoma and perforated Mooren's ulcer each.

In children ( $\leq 16$ years of age; $\mathrm{n}=28)$ the mean age was 7.3 years (SD 4.1). There were 20 males $(71.4 \%)$ and 8 female $(28.6 \%)$. The male to female ratio was $2.5: 1$. The indications for surgery were ruptured globe and anterior staphyloma in 10 patients (35.7\%) each, tumor in $4(14.3 \%)$, panophthalmitis in $3(10.7 \%)$ and painful blind eye (mooren's ulcer) in 1 (3.6\%) of the children respectively.

Surgeries performed in children were evisceration in 20 $(71.4 \%)$, enucleation in $7(25.0 \%)$ and exenteration in $1(3.6 \%)$ patient. Figure 1.

In adults $(n=39)$ there were 26 males $(66.7 \%)$ and 13 females (33.3\%). The most common indication for removal of adults' eyes was panophthalmitis in 18 (46.2\%) followed by ruptured globe in $16(41.0 \%)$. Others were anterior staphyloma in $4(10.3 \%)$ and painful blind eye due to advanced glaucoma in $1(2.6 \%)$ of the adults. Evisceration was performed in $35(89.7 \%)$ and enucleation in 4 (10.3\%) of adults.

Analysis of gender distribution of the indications for eye removal showed that ruptured globe was more common in males $(21,47.5 \%$ versus $5,23.8 \%)$. The relative 


\section{Indications for Surgical Removal of Eyes in a Tertiary Institution in North Eastern Nigeria}

Olatunji F.O., Ibrahim F.U., Ayanniyi A.A., Azonobi R.I., Tukur R.B., Maji D.A.

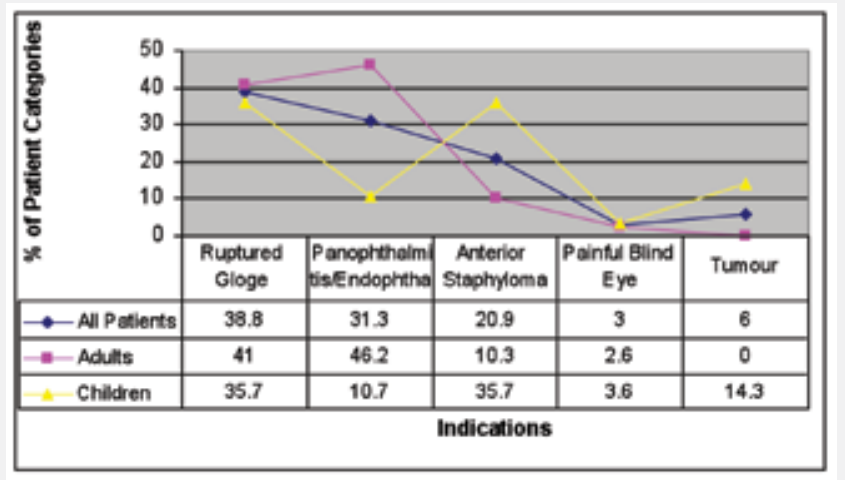

Fig. 1: Relative distribution of the various indications for eye removal in all patients, adults and children

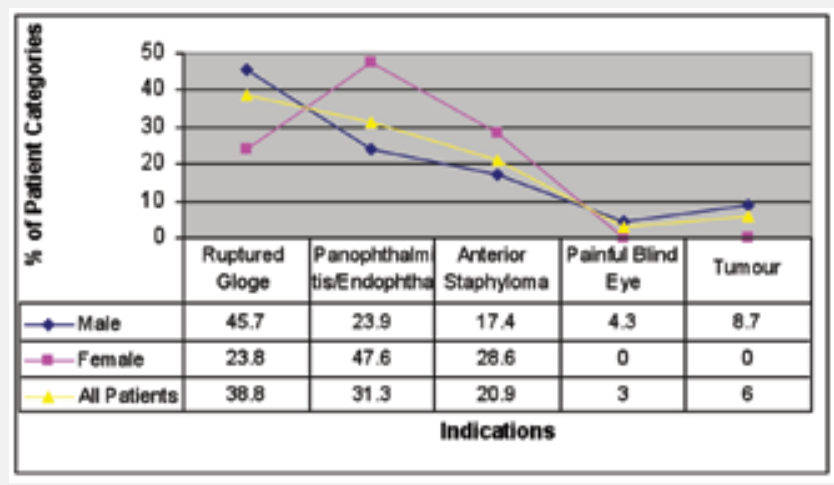

Fig.2: Gender distribution of the patients whose eyes were removed

frequencies of other indications for eye removal are as shown in figure 2 .

\section{Discussion}

The period under review, January 2002 to December 2008, represented the beginning of ophthalmically functional period in the hospital. The periods during which many surgeries were performed coincided with those periods that ophthalmologists (visiting and/or resident) were present at the centre.

The finding of destructive eye surgeries forming $8.9 \%$ of all ophthalmic surgeries in the period under review is similar to the findings of other workers in Nigeria $(4,5)$, but contrasts sharply to the prevalence of $0.17 \%$ found by workers in India (14). These reflect the relatively better developed eye care delivery system in that region.

The male preponderance is this study is also consistent with previous work in Nigeria $(2,4,5)$, rest of Africa
$(12,15)$ and Israel $(16)$. Trauma was the most common indication for eye removal in this study as in several previous reports $(2,3,5,6,17-22)$. Trauma is more common in adult $(41.0 \%)$ than in children $(35.7 \%)$ and in males $(45.7 \%)$ than females $(23.8 \%)$. This may be due to the more frequent exposure of males to adventurous activities. The sources of trauma in the present study were mainly from stick, cattle and goat horns, and less commonly from assaults, armed robbery attacks, political and cult violence as found by others $(4,5,23)$. The community around the study centre are mainly agrarian communities of mainly Hausa/Fulani extractions, many of whom are farmers and cattle rearers. Infection accounted for $31.3 \%$ of eye removal in this study. This is similar to the findings of other workers $(4,5,6)$ in Nigeria. Infection remains a major cause of eye removal in developing countries mainly due to poverty and inaccessible eye services.

Anterior staphyloma ranked as the 3rd commonest indication for eye removal. Corneal ulceration mostly from measles and Vitamin A deficiency since childhood was documented to be the cause in 7 of the patients.

Workers in Nigeria $(4,5)$ as well as in the Gambia (9) found anterior staphyloma to be a common indication for eye removal. The finding that more female eyes were removed for anterior staphyloma than those of males point to their greater desire for better cosmetic appearance.

Tumor constituted only a small percentage $(6.3 \%)$ of the indications in the present study. This is rather surprising since Retinoblastoma which forms the bulk of childhood tumors is linked to consanguineous marriage which is a common practice in the study area. In the works of Eze et al tumor accounted for $2 \%$ to rank 3rd as the most common indication(4). However it accounted for $30.4 \%$ in Ife (14) south western Nigeria ranking 2 nd only to trauma. All cases of tumor were in children and all were males. Tumor diagnoses were presumptive since no histological confirmation was available.

Painful blind eye was the least common indication accounting for $3.2 \%$. It was the second $(21.9 \%)$, third $(16.3 \%)$ and 4 th (13.2\%) most common cause in works of Pandey (13), Ademola-popoola (6) and Eze et al respectively (4).

Evisceration was performed in $51(81.0 \%)$ enucleation in $11(17.5 \%)$ and exenteration in $1(1.6 \%)$ of the patients. Many workers $(3,8)$ reported higher frequencies 
of evisceration compared to enucleation. In children, enucleation is more often performed than evisceration since ocular tumor is often the indication for eye removal in childhood $(6,14)$.

In conclusion, trauma, panophthalmitis, and anterior staphyloma were the major indications for eye removal. Most of the indications for eye removal were avoidable.

\section{References}

1. Custer PL. Enucleation: Past, present, and future. Ophthalmic Plast Reconstr Surg 2000;16:316.

2. Mpyet $\mathrm{C}$, Wade $\mathrm{P}$, Ramyil A. Indications for surgical removal of the eye in adults a five-year review. Niger J Med. 2008;17(1):107-9.

3. Gaton DD, Ehrlich R, Muzmacher L, Hamel N, et al. Enucleations and eviscerations in a large medical center between the years 1981 and 2007. Harefuah. 2008;147(10):758-62, 840 .

4. Eze B1, Maduka-Okafor FC, Okoye IO, et al. Surgical Indications for Eye Removal in Enugu, South Eastern Nigeria. Nig J of Ophthal 2007; 15(2):44-48.

5. Enock ME, Omoti AE, fuh UC, et al. Indications for Surgical Removal of the Eye in Irrua, Nigeria. Nigeria Journal of Ophthalmology 2008;16-19.

6. Ademola -Popoola DS and Owoeye JFA. Indications for Evisceration and Enucleation of the Eye at Ilorin, Nigeria: A Ten-year Review. The Trop J of Health Sci.2005:12: 7-9.

7. Scat Y, Liotet S, Bellefqih S. Etiology of enucleations. A propos of 3,246 cases. J Fr Ophtalmol. 1996;19(4):242-7.

8. Hansen AB, Petersen C, Heegaard S, et al. Review of 1028 bulbar eviscerations and enucleations. Changes in etiology and frequency over a 20-year period . Acta ophthalmol Scand. 1999;77(3):331-5.

9. Rasmussen, M. L. R., Prause, J. U., Johnson, M., et al. Review of 345 eye amputations carried out in the period 1996-
2003, at Rigshospitalet, Denmark. Acta Ophthalmologica, 2010; 88: 218-221.

10. Moshfeghi DM, Moshfeghi AA, Finger PT. Enucleation. Surv Ophthalmol 2000;44:277-30.

11. Sigurdsson H, Thórisdóttir S, Björnsson JK. Enucleation and evisceration in Iceland 1964-1992. Study in a defined population. Acta Ophthalmol Scand. $1998 ; 76(1): 103-7$.

12. Dawodu OA, Hannah BF. Enucleation and evisceration in the Gambia, Nig J of Ophthal 2000; 8(1):29-33.

13 Kyari F, Gudlavalleti MV, Sivsubramaniam S, et al. Prevalence of blindness and visual impairment in Nigeria: the National Blindness and Visual Impairment Study. Invest Ophthalmol Vis Sci. 2009;50 (5):2033-9.

14. Vemuganti GK, Jalali S, Honavar SG, et al. Enucleation in a tertiary eye care centre in India: prevalence, current indications and clinicopathological correlation. Eye. 2001;15:7605.

15. Davenger M. Causes of enucleation in Uganda Br J Ophthalmol 1970; 54:252-255.

16. Batten KL. Causes of enucleation as seen in Jerusalem $\mathrm{Br}$ J Ophthalmol 1971; 55:174-6.

17. Adeoye AO, Onakpoya OH. Indication for eye removal in IleIfe, Nigeria. Afr J Med Sci. 2007;36(4):371-5.

18. Viviane RC, Ana Christina CN, Sigmar De Mello R. Evaluation of the etiology of ocular globe atrophy or loss. Braz Dent J 2005; 16(3): 103-6.

19. Kaimbo K. Causes of enucleation in Zaire. J Fr Ophthalmol 1988; 11(10):677-80.

20. Schien OD, Hibbered PL, Shingleton BJ, et al. The spectrum and burden of ocular injury. Ophthalmology 1988; 95:3005.

21. Me Ewen J. Eye injuries: A prospective surgery of 5671 cases. Br J Ophthalmol 1989; 73:888-94.

22. Hail MmAlemayehu W. Cases of removal of the eye in Ethiopia. East Afr Med J 1995: 72 (11): 29-33. 